Erratum

\title{
Erratum: Obalová, L.; Klegova, A.; Matějová, L.; Pacultová, K.; Fridrichová, D. Must the Best Laboratory Prepared Catalyst Also Be the Best in an Operational Application? Catalysts 2019, 9, 160
}

\author{
Lucie Obalová ${ }^{1, * \mathbb{C}}$, Anna Klegova ${ }^{1}$, Lenka Matějová ${ }^{1}$, Kateřina Pacultová ${ }^{1} \mathbb{1}$ and \\ Dagmar Fridrichová ${ }^{1,2}$ \\ 1 Institute of Environmental Technology, VŠB - Technical University of Ostrava, 17. listopadu 15/2172, \\ 70800 Ostrava, Czech Republic; anna.klegova@vsb.cz (A.K.); lenka.matejova@vsb.cz (L.M.); \\ katerina.pacultova@vsb.cz (K.P.); dagmar.fridrichova@vsb.cz (D.F.) \\ 2 Centre ENET, VŠB-Technical University of Ostrava, 17. listopadu 15/2172, 70800 Ostrava, Czech Republic \\ * Correspondence: lucie.obalova@vsb.cz
}

Received: 15 April 2019; Accepted: 18 April 2019; Published: 29 April 2019

check for updates

The authors wish to make the following erratum to this paper [1]:

There is one mistake in this article [1]. On page 16, there is a correction needed in the Funding details:

“This research was funded by ERDF OP RDE project No. CZ.02.1.01/0.0/0.0/15_019/0000853 and by OP RDI project No. CZ.1.05/2.1.00/19.0389."

This should be replaced with:

“This research was funded by ERDF OP RDE project No. CZ.02.1.01/0.0/0.0/16_019/0000853 and by OP RDI project No. CZ.1.05/2.1.00/19.0389."

The authors would like to apologize for any inconvenience caused to the readers by these changes. The manuscript will be updated and the original will remain online on the article webpage https://www.mdpi.com/2073-4344/9/2/160.

\section{Reference}

1. Obalová, L.; Klegova, A.; Matějová, L.; Pacultová, K.; Fridrichová, D. Must the best laboratory prepared catalyst also be the best in an operational application? Catalysts 2019, 9, 160. [CrossRef]

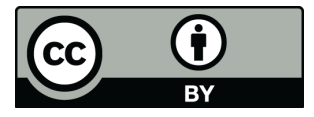

(C) 2019 by the authors. Licensee MDPI, Basel, Switzerland. This article is an open access article distributed under the terms and conditions of the Creative Commons Attribution (CC BY) license (http://creativecommons.org/licenses/by/4.0/). 